\title{
Physical activity and exercise interventions for people with rare neurological disorders: a scoping review of systematic reviews
}

\section{CURRENT STATUS: POSTED}

Research Square

Valentina Buscemi

University College London Hospitals NHS Foundation Trust

Annette Boaz

Kingston University

Helen Dawes

Oxford Brookes University

Thomas Jaki

Lancaster University

Fiona Jones

Kingston University

Rachel Lowe

Cardiff University

Jonathan Marsden

University of Plymouth

Lorna Paul

Glasgow Caledonian University

Rebecca Playle

Cardiff University

Elizabeth Randell

Cardiff University

Mike Robling

Cardiff University

Lynne Rochester 
Newcastle University

Monica Busse

Cardiff University

Gita Ramdharry

University College London Hospitals NHS Foundation Trust National Hospital for Neurology and Neurosurgery

gita.ramdharry@nhs.netCorresponding Author

ORCiD: https://orcid.org/0000-0001-9344-0301

\section{DOI:}

$10.21203 / \mathrm{rs} .2 .18082 / \mathrm{v} 1$

\section{SUBJECT AREAS}

Internal Medicine

\section{KEYWORDS}

co-production, neurological conditions, physiotherapy, behavioural change, patient and public involvement 
Abstract

Background: People living with rare neurological conditions (RNCs) often face common physical, cognitive and psychological challenges that lead to reduced physical activity and associated deconditioning. Physical activity interventions are routinely utilised to address disease specific limitations with the intention of promoting participation in people with RNCs. This scoping review aimed to synthesise the body of evidence for such interventions as they are applied across a wide range of RNCs.

Methods: We undertook a scoping review of systematic reviews of any type of physical activity and exercise interventions for adults with neuromuscular diseases, motor neurone disease, Huntington's disease, progressive supranuclear palsy, multiple system atrophy, inherited ataxias and hereditary spastic paraplegia. The reviews were included if they reported at least one outcome that aimed to increase physical activity level at either the body structure/function, activity and/or participation levels.

Results: Sixty-two articles were full-text screened of which 27 were included. Most studies involved interventions in people with neuromuscular diseases. No reviews of interventions in hereditary spastic paraparesis were identified. The majority of reviews included studies of structured exercise using outcome measures at the level of body function and functional activity. Interventions were grouped as: i) combined interventions; ii) muscle strength training; iii) respiratory training; iv) aerobic training. Frequency, intensity, time and type of structured exercise utilised varied considerably across studies. Most studies were methodologically limited by small sample sizes, variation in exercise dose and training duration.

Conclusions: To date, primary attention has been given to structured exercise interventions, which have demonstrated to have a low to uncertain level of evidence. Novel approaches to implementing common interventions and modalities are needed to increase accessibility and engagement in physical activity irrespective of disease type. Further exploration is warranted to achieve consensus on outcome measures that reflect areas of importance and relevance to people with RNCs. Introduction 
Rare neurological conditions (RNCs) describe a heterogeneous group encompassing disorders such as neuromuscular diseases (NMDs), motor neurone disease (MND), Huntington's disease (HD), progressive supranuclear palsy (PSP), multiple system atrophy (MSA), inherited ataxias and hereditary spastic paraplegia (HSP). As a collective group, all rare conditions have a global prevalence of 40 cases per 100,000 population (1), and it is estimated that $5-8 \%$ of the European population are affected by a rare disease (2).

Due to their progressive long-term nature, RNCs taken together cause a significant cost burden on health and social care services (for example due to delays in obtaining a diagnosis and consequent long-term care) and, and incur hidden costs related to informal care and family support (3). For this reason, experts in this field recommend a united approach that takes into account the entire spectrum of RNCs, to enable appropriate understanding and management of patients with these diseases (2).

People with neurological disabilities are as twice as likely to be inactive compared to non-disabled people (4). This sedentary lifestyle increases the risk for the development of non-communicable diseases, with an associated $20-30 \%$ increased risk of all-cause mortality (5). Most importantly, people living with RNCs face common challenges in daily life, not only physical (e.g. fatigue, poor balance, pain), but also cognitive and psychological (e.g. low mood or motivation), resulting in a great reduction in participation in daily activities and a sedentary lifestyle (6-11).

Physical activity and exercise interventions tailored to people living with RNCs are generally promoted in national and international guidelines (12-14). These interventions widely comprise "Any bodily movement produced by skeletal muscles that requires energy expenditure" and any type of structured exercise (15) including gait and balance training, video-gaming (16-18) and cognitive behaviour interventions (19-21). However, although physical activities are promoted as an essential part of the clinical management across RNCs, evidence supporting physical activity interventions is still lacking in these conditions (22-27). To date, there are significant gaps in understanding about which types of activities maintain physical functioning and increase participation in activities and quality of life across RNCs. 
Previously, systematic reviews have investigated the level of evidence for physical interventions in specific RNCs. For example, reviews have investigated the safety and efficacy of strength and aerobic training in people with NMDs $(27,28)$, while another review assessed the effect of respiratory function in patients with MND (29).

As no reviews have collectively synthesised the existing evidence in support of physical activity and exercise interventions across the wide spectrum of RNCs, the overarching aim of this scoping review was to synthesise the body of evidence in relation to those interventions that seek a change in physical conditioning, functioning and participation in those living with RNCs.

\section{Methods}

\section{Protocol}

This scoping review of systematic reviews, was conducted according to the methodology outlined in the Joanna Briggs Institute (JBI) Reviewers' Manual (30) and followed the framework proposed by Arksey and O'Malley (31) and detailed by Levac, Colquhoun and O'Brien (32). Arksey and O'Malley's framework (31) consisted of six steps: (i) Identifying the research question; (ii) identifying relevant studies; (iii) study selection; (iv) charting the data; (v) collating, summarizing and reporting the results; (vi) consultation.

The review protocol was designed with experts in the field of rehabilitation in RNCs, who were consulted to identify inclusion/exclusion criteria, data extraction and charting process (protocol registered on Open Science Framework: https://osf.io/4cr32/).

\section{Step 1: Identifying the research question}

The research question of this scoping review was developed through discussions with stakeholders including patients and support groups representatives of seven rare conditions (Muscular Dystrophy Association, Ataxia UK, Hereditary Spastic Paraplegia support group, Progressive Supranuclear Palsy Association, Huntington's disease Association, Multiple System Atrophy Trust, Motor Neurone Disease Association). 
This scoping review asked the following research questions: i) What are the common exercise and physical activity interventions for people living with RNCs? 2) What are the characteristics of these interventions in terms of frequency, intensity, time and type? 3) What outcome measures were used to measure intervention efficacy?

\section{Step 2: Search strategy}

A three-phase search strategy was designed, as outlined in the Guidance for Conducting Systematic Scoping Reviews (33) and informed by advice from a university librarian. A preliminary search was conducted using keywords, such as physical therapy, physical activity, physiotherapy or exercise.

Relevant keywords in the title and abstracts of systematic reviews were extracted to form a second list of terms that was used to undertake the final searches through the following databases: Pubmed, Embase and CINAHL (full search lists can be found in Additional file 1).

Finally, the reference list of all identified systematic reviews was hand-searched for additional studies. Authors of reviews were contacted for further information, as required.

Step 3: Selecting studies

Inclusion and exclusion criteria

1. Full-text systematic reviews (including meta-analyses) in English from 2008 to 2018 , that reported on physical activity and exercise intervention studies (including randomised controlled trials, quasi-experimental studies, controlled and pre-post designs) were included.

2. Systematic reviews reporting at least one outcome measure on physical activity and/or exercise. We utilised an evaluation framework following the International Classification of Functioning, Disability and Health (ICF) (34) and we divided the outcome measures according to their level of body structure/function impairments (e.g. manual muscle strength testing) or limitations in functional activities and 
participation restrictions (e.g. daily steps count or measures of functional

independence).

3. Systematic reviews that included observational studies were considered for inclusion if they selectively reported on interventional evidence, whilst those solely reporting on findings from observational studies were excluded. Pharmacological interventions were excluded.

4. Scoping reviews and literature reviews were excluded.

Population

Adults (individuals older than 18 years) at study entry, with one of the following neurological conditions (either at early or advanced stages): ataxias (e.g. Friedreich's ataxia), HSP, HD, NMD (e.g. polyneuropathies, myasthenia and muscular dystrophies), MND, atypical Parkinsonisms (e.g. MSA, PSP).

Concept

Systematic reviews of interventions that aimed to increase the quantity (e.g. steps count) or change the quality (e.g. confidence in doing activities) of physical activity at either the body structure/function or activity and/or participation levels (ICF framework) were included. Exercise interventions that sought a change in physical fitness (e.g. using physiologic parameters) were also included.

Systematic reviews of interventions with a control arm that fell within the category of regular physical activity (e.g. treatment as usual in a clinical setting, or every-day life activity) and/or active interventions that differed quantitatively (in terms of intensity, frequency or duration of physical activity) or qualitatively (e.g. less cognitively challenging) from the intervention of interest, were included.

Outcomes related to physical activity (primary outcomes) and indirect outcomes (secondary 
outcomes), such as fatigue and psychological symptoms (e.g. depression), were extracted from the relevant studies. Outcome measures were grouped according to the ICF framework, under three main domains: participation restrictions, limitations in functional activities, and body structure and body function impairments.

\section{Context}

Any type of setting (e.g. home, primary health care or the community) and country were included in the current review.

\section{Screening}

Titles and abstracts were screened manually for eligibility by one reviewer (VB) against inclusion/exclusion criteria and those that were clearly outside the scope of the review were excluded. A second reviewer (GR) independently screened a random sample of $10 \%$ of the total papers (by titles and abstracts) for inclusion or exclusion. The full-text of eligible papers was extracted and checked by the first reviewer, with any concerns about inclusion discussed with two members of the team and resolved by consensus. The screening process was detailed, reporting the number of studies selected against inclusion criteria, using the Preferred Reporting Items for Systematic Reviews and MetaAnalyses (PRISMA) flow diagram (35).

\section{Step 4: Charting the data (data extraction)}

Data extraction from each eligible review was conducted by one reviewer (VB). The data extraction process included: (i) an overview of the main characteristics of included reviews such as authors, year of publication, type of condition, type of review (systematic review with or without meta-analysis), aim, inclusion and exclusion criteria, number of studies retrieved and included/excluded, quality and bias assessment method; ii) characteristics of studies included for each review, such as study designs, number and participant characteristics, controls, outcome measures, disease-specific interventions (using the FITT model - frequency, intensity, time and type), settings and study quality; 
(iii) a summary of key findings, limitations and recommendations for each review.

Step 5: Collating, summarising and reporting data

A descriptive synthesis of common interventions was produced, accompanied by charting tables. A summary of the outcome measures utilised was presented using charts and tables to provide an overview of common assessment tools across different conditions, as outlined in the JBI Reviewers' Manual (30).

Step 6: Consultation

Experts in the field of rehabilitation in RNCs were consulted to discuss the review findings.

\section{Results}

Search and selection of included reviews

Database searches identified 5435 articles, and, after removing duplicates, 4433 were screened by titles and abstracts, leaving 62 articles for full-text eligibility assessment. After full-text screening, 27 articles were included for the narrative synthesis. No additional sources were identified from the reference lists of included studies. Reasons for exclusion were: conference abstract $(\mathrm{N}=11)$, no fulltext available $(\mathrm{N}=2)$, conditions, research design and outcome measures described did not meet the inclusion criteria $(N=13)$, previous version of included systematic review $(N=6)$ and systematic reviews included the same studies present in more recent reviews $(N=3)$ (Fig.1). The second reviewer (GR) screened 443 studies randomly selected from the total records (without duplicates) and did not identify any further eligible articles.

\section{Figure 1. PRISMA flow diagram}

Included systematic reviews

An overview of the main characteristics of included reviews is outlined in Table 1. More detailed information is presented: i) for each review in Additional file 2 (i.e. authors, year of publication, type 
of condition); ii) for studies included in each review in Additional file 3 (e.g. study designs, number and participant characteristics); (iii) in a format of summary of key findings, limitations and recommendations for each review in Additional file 4.

\section{Table 1. Review characteristics of included studies}

Out of 27 articles, 16 involved a narrative synthesis $(\mathrm{N}=16)$ and were published from 2013 onwards. Most systematic reviews aimed to examine the evidence for an effect of any type of intervention $(\mathrm{N}=$ 9), exercise training $(N=6)$ or a rehabilitation intervention $(N=4)$ in rare neurological conditions. Most studies investigated people with NMDs $(N=13)$, including a number of muscle diseases (e.g. myotonic dystrophy) ( $\mathrm{N}=1)$, myotonic dystrophy and Welander distal myopathy $(\mathrm{N}=1)$, muscular dystrophy $(\mathrm{N}=1)$, Welander distal myopathy, muscular dystrophies and Hereditary inclusion body myopathies $(\mathrm{N}=1)$, idiopathic inflammatory myopathies $(\mathrm{N}=1)$, Charcot-Marie-Tooth disease $(\mathrm{N}=3)$, McArdle disease $(N=1)$, Guillain-Barre' Syndrome $(N=2)$, critical illness myopathy and polyneuropathy $(\mathrm{N}=1)$ and Postpolio syndrome $(\mathrm{N}=1)$. More than half of reviews included one to five intervention studies for each review $(\mathrm{N}=18)$. Twenty systematic reviews included at least one RCT in their reports, whilst the remaining studies included at least a quasi-randomized controlled design $(\mathrm{N}=$ $1)$, observational prospective design $(\mathrm{N}=1)$, case-control design $(\mathrm{N}=3)$ or pre-post design $(\mathrm{N}=2)$. Some intervention studies were reported in multiple reviews. In particular, Lui and Byl (36) and Arbesman and Sheard (37) included one randomized trial (38) and a quasi-randomized trial (39) that were discussed in Dal Bello-Haas et al. (40). Therefore, the two studies were described only once in Dal Bello-Haas et al's review (40). In Marquer, Barbieri and Pe'rennou (41), four intervention studies were relevant for the aim of the present scoping review, however, only one was reported in the result section, as the remaining three studies were already presented in Fonteyn et al. (42).

The systematic review with the smallest number of participants included 18 individuals in total (43), whilst the one with the largest sample included 779 (44), followed by 757 (45) and 435 (16), which investigated, respectively, the effect of multidisciplinary care in individuals living with MND (44), and 
any type of interventions in individuals with NMDs (45), and physical therapy in people with HD (16) (see Additional file 2).

In line with the stated aims of the review, findings have been grouped by types of interventions and conditions (Fig. 2). Systematic reviews identified the following types of training: muscle strength training $(N=2)$ and aerobic training $(N=1)$ in individuals with NMDs; respiratory training in individuals with MND $(N=2)$; combined interventions in individuals with NMDs $(N=10)$, Ataxias $(N=$ 4), MND $(N=4), H D(N=2)$ and PSP $(N=2)$. FITT characteristics varied considerably, both within and between reviews, however, they are reported in Table 2 where possible, for each intervention.

\section{Figure 2. Summary of types of interventions per condition}

Figure's legend: NMDs = neuromuscular diseases; MND = motor neurone disease; HD = Huntington's disease; PSP = progressive supranuclear palsy

\section{Combined interventions}

Twenty-two reviews across all RNCs identified in this scoping review included combined interventions. Frequency, intensity and time varied considerably between studies, with interventions lasting between one to 260 weeks, ranging between one to seven sessions per week, with each session lasting 10 minutes to eight hours (Table 2). Similar interventions across conditions were: muscle strength exercises, stretching, aerobic training, multidisciplinary interventions and gait training. Gait training and balance exercises were reported in all conditions with the exception of MND. Details on intervention intensity and frequency were not routinely reported, especially in the MND and ataxia reviews.

\section{Table 2. Number of reviews per condition and FITT characteristics for combined interventions}

Ten reviews $(25,27,43,45-51)$ addressed the effect of combined interventions in individuals with NMDs (Charcot-Marie-Tooth disease, Guillain-Barre' Syndrome, myotonic dystrophy and Welander distal myopathy, idiopathic inflammatory myopathy, post-polio syndrome, Welander distal myopathy, 
Becker muscular dystrophy, limb-girdle muscular dystrophies, hereditary inclusion body myopathies, polymyositis and dermatomyositis, facioscapulohumeral muscular dystrophy, mitochondrial myopathy, critical illness myopathy and polyneuropathy).

Combined interventions in NMDs included: hand exercises (i.e. isolated and mass movements with silicone-based putty combined with resistance and stretching exercises); aerobic training (e.g. walking, bicycle training, step aerobics, home training of stationary bicycle ergometer); body weight support exercises, muscle strength training, strength exercises combined with breathing exercises, stretching, education, self-care education combined with home training, psychological and social support, passive or active motion sessions, functional exercises, multidisciplinary goal-oriented rehabilitation based on functional treatment, physical therapy training based on neurodevelopment sequences, positioning, wobble board, gait training and occupational therapy.

Four reviews $(36,37,40,44)$ addressed the effect of combined interventions in individuals living with MND, including: supervised proprioceptive neuromuscular facilitation (PNF) patterns combined with strength and a home exercise programme (stretching combined with a range of motion exercises), slow reversals resistance techniques, treadmill with biphasic positive airway pressure, individualized and progressive exercise, moderate intensity, moderate load resistance exercises and daily stretching exercises, endurance type exercises for limbs and trunk. One review investigated the effect of multidisciplinary care, including a consultant in rehabilitation, occupational therapist, physical therapist, speech-language pathologist, dietician, and social worker (44).

Two reviews $(16,52)$ addressed the effect of combined interventions in individuals living with HD, including: exercise individualised addressing maintenance of functional ability, flexibility, strength, video based exercise designed to reduce impairment and promote balance, physiotherapist instructed stretches, coordination, balance, one leg balance and tandem walking and upper limb ball exercises, respiratory intervention, facial exercise, whole body exercises in lying standing and sitting for gait, transfer training, postural training, a multi-sensory stimulation intervention, gait therapy, cycling, resistance exercises and aerobic exercise, use of videogames, PNF intervention, functional activities, combination with occupational therapy and social activities. 
Four systematic reviews $(41,42,53,54)$ addressed the effect of combined interventions in individuals living with ataxias, including: coordination, balance, and muscular conditioning exercise, physical therapy, with a focus on balance, gait, general conditioning, muscle strength and range of motion, coordinative training with the main goal of being able to activate and engage/control mechanisms of balance, multi-joint coordination, occupational therapy (daily activities such as accessing to food, clothing, personal hygiene, and leisure were some of the main disabilities focused by these patients). Two systematic reviews $(55,56)$ addressed the effect of combined interventions in individuals living with PSP, including: balance training complemented with eye movement and visual awareness training (versus balance training alone and limb coordination activities), fine motor activities, tilt board balancing, ambulation training, exercises to improve strength and coordination, static and dynamic balance, resistive and isokinetic exercises, Biomechanical Ankle Platform System, physical exercises, modified body weight support treadmill, wearable audio-biofeedback device/Dynamic Antigravity Postural System; Vibration Sound system, exercise programme of stretching, treadmill with and without body weight support, physical therapy exercises and Xbox Kinect, Virtual Gaming System, robot-assisted gait training, using end-effector robotic rehabilitation locomotion training (GEO system device), multidisciplinary intensive rehabilitation treatment.

\section{Muscle strength training}

Two systematic reviews $(28,57)$ included interventions lasting from 12 to 52 weeks and investigating strength training in individuals living with NMDs, including: general muscle involvement or selected muscles, dynamic and isometric strength training with weights. Frequency of interventions was not reported in both studies, while intensity ranged between 30 and 60 minutes per session.

\section{Aerobic training}

One systematic review included three non-randomised studies lasting 8 to 32 weeks and investigating aerobic training such as walking and cycling in individuals living with NMDs. Each session lasted between 45 and 60 minutes with a frequency of three to five times per week (58). 
Respiratory training

Two systematic reviews included studies lasting from 12 weeks to 32 months and investigating respiratory training in individuals living with MND, including: respiratory training muscle and yoga breathing technique. In one study, duration per session was 10 minutes, while other studies reported 10 to 15 repetitions per sessions, two to five times a day, every day $(29,59)$.

\section{Outcome measures}

A total of 189 outcome measures were identified across the included reviews. Of these, the majority were related to body function impairments (47\%) and limitation in functional activities (27\%), followed by participation restrictions (6\%) and body structure impairments (5\%). Two domains did not fall into the ICF classification and were categorised as "Other" (e.g. Goal attainment score) (8\%), and "Disease-specific" questionnaires (e.g. Unified Huntington's Disease Rating Scale or Scale for the Assessment and Rating of Ataxia) (7\%). The full list of the outcome measures can be found in Additional file 5 .

Most reviews included studies using outcome measures related to the domain of body function impairments ( $N=26$ ), followed by limitation in functional activities ( $N=17$ ), participation restrictions $(N=13)$ and body structure impairments $(N=5)$ (Table 3$)$. Notably, none of the outcome measures included were agreed with the involvement of service users or members of the public.

Eleven reviews included studies using disease-specific outcome measures, while in six reviews, studies used other measures that did not fall into the ICF domains (i.e. in the "Other" category), such as goal attainment or hospital readmissions and length of stay. Most reviews used a combination of three to five different domains $(\mathrm{N}=17)$, while in eight reviews two domains were present. One domain was identified in two reviews (Table 3 )

\section{Table 3. ICF domains identified for each study}

\section{Discussion}


The aim of this scoping review was to synthesise the body of evidence in relation to physical activity and exercise interventions utilised across a wide range of RNCs. As part of this, the review sought to explore the range and focus of outcome measures used in these studies.

Rare diseases under study

The majority of the studies were conducted in people with NMDs, followed by MND, hereditary ataxias, HD, and PSP. The prevalence of studies identified in NMDs was expected, due to the fact that they do not represent only one disease entity, but approximately 60 diseases under one umbrella that affect the peripheral nerves, neuromuscular junction or muscles tissue (60). Some of the systematic reviews identified explored specific groupings within NMDs, for example only muscle disease (27) or inherited peripheral neuropathy $(48,57)$. Thus, the reviews do not represent interventions across a range of NMDs, and may falsely inflate the apparent number of reviews, when in reality they focus on individual neuromuscular conditions.

HSP was one of the included conditions, however, no systematic reviews were identified at the time of searches. The overall literature in this condition is limited to case studies of rehabilitation

interventions (61) and small studies of hydrotherapy (62) or robot gait training $(63,64)$, as confirmed in a recent systematic review, identified subsequently to our scoping review searches (23). The authors of this recent systematic review rated the overall quality of physical interventions in HSP as low. HSP has a similar prevalence to HD and PSP, so it is unclear why there is a paucity of literature in physical activity or exercise interventions in this group (65).

\section{Physical Activity Interventions}

Most reviews included studies of structured exercise using body function and functional activity primary outcomes. These studies investigated muscle strength training, aerobic training, respiratory training and combined interventions encompassing muscle strength exercises, stretching, aerobic training, multidisciplinary interventions and gait training. The interventions were prescribed and progressed by health care or exercise professionals and followed the FITT principles. Many were 
standardised programmes, but variability existed in the prescription with only approximately one third adhering to the American College of Sports Medicine recommendations (66). Variation was also seen in the type of training with resistance training (skeletal or inspiratory muscles), aerobic training or a mixture of the two. In addition, functional training, using gait trainers, was included in some reviews. Some were used to increase aerobic capacity and others aimed to improve walking parameters such as daily step counts, speed, or stance/swing time.

The level of evidence mostly ranged from low to uncertain and a common finding across the reviews was the methodological limitations, characterised by small sample sizes, variation in exercise dose and training duration. Despite these limitations, some reviews reported on adverse events and recommended exercise to be safe $(27,36,45,46,50,58)$. Other reviews recommended caution when interpreting findings $(16,48,49,53)$, due to heterogeneity in intervention characteristics, outcome measures, insufficient high-quality studies and likelihood of Type II errors.

In most reviews, authors warranted further research for more definitive answers on intervention effectiveness. However, in Charcot-Marie-Tooth disease and cerebellar ataxias, there was low to moderate evidence of efficacy of structured exercise $(41,42,47,48)$ whilst, in MND, structured exercise was recommended for inclusion in rehabilitation and management of these diseases $(29,36)$. Very few reviews focused on behaviour change interventions to increase participation in physical activity and/or structured exercise. Behaviour change interventions are psychology-based and promote changes in individual capability and motivation to engage in a certain activity, and provide opportunity to make the behaviour change possible (67). They have been investigated in other neurological conditions, such as multiple sclerosis and stroke, and long-term conditions such as diabetes and prostate cancer (68-72). In our scoping review, there was no evidence of behaviour change interventions based on participant choice, and strategies to increase individual self-efficacy and help patients make decisions on activities they would feel motivated to try. Education and multidisciplinary goal setting were used in trials of rehabilitation on Guillain-Barre' syndrome, but this pertained to shorter term rehabilitation programmes (i.e. 12 weeks) (51), as opposed to longer term behaviour change. 
Since this scoping review was undertaken, additional systematic reviews have been published. There has been an update to the Cochrane review on exercise in muscle diseases (22) in particular in spinal muscular atrophy. The review identified one randomised-controlled trial (73) investigating the effects of a home-based, muscle strength intervention combined with cycle ergometer training programme in 14 people with spinal muscular atrophy for six months (22). In the above study, no detectable changes were identified on measure of function, cardiopulmonary exercise capacity, quality of life and fatigue and the authors graded the study quality as very low, and warranted future well-designed and adequately powered studies.

Two systematic reviews have been conducted recently on the effect of exercise in HD. The first review meta-analysed the evidence for efficacy and safety of physical exercise interventions across six chronic brain disorders including HD (74). The overall effect size across studies was positive on depressive symptoms, quality of life, cognition (e.g. attention and working memory, executive functioning), however, separate analyses did not show positive effects on these outcomes in individuals with HD. A second systematic review investigated the effect of exercise on high-level mobility (e.g. running or jumping) in individuals with neurodegenerative disease, such as multiple sclerosis, Parkinson's disease, HD and degenerative cerebellar disease (24). However, no new studies involving participants living with rare conditions were identified in the review, as the two intervention studies included $(17,75)$ were reviewed in two previous systematic reviews included in the present scoping review $(16,53)$.

\section{Outcome measures}

Similar to the interventions described in the present review, outcome measures were highly variable across the included systematic reviews and mostly assessed changes at the levels of body function (e.g. manual muscle strength testing) and functional activities (e.g. 6 minute walking test), perhaps reflecting the intent of researches to measure efficacy of structured exercise interventions. The few outcomes identified at the level of participation primarily measured quality of life, including life satisfaction and well-being, and were documented in less than half of reviews. The major focus on 
function and activity measures, as opposed to participation in activities, highlights a lack of attention, and perhaps understanding, on the non-motor effects of physical activity and exercise, an area that is critically important for people with RNCs. Exploring the areas for change, important for people living with RNCs, represents an important step that requires attention in prospective evaluations to ensure that the research is relevant to study participants, and ultimately, in clinical practice (76). Further exploration is needed to achieve consensus between researchers and members of the public on recommended participatory focussed outcome measures. Furthermore, given the common challenges experienced by people living with RNCs, alongside the importance to maintain a united approach across conditions, there is an urgent need to define a core and standardised outcome measure set across the wide spectrum of RNCs. This outcome measure set would greatly benefit the synthesis of future studies on physical activity and exercise interventions.

\section{Conclusion}

Although our aim was to include physical activity interventions of any kind, the vast majority of systematic reviews identified in this scoping review encompassed structured exercise that aimed to change physical activity measured at the level of body function and functional activity. Structured exercise can be considered one way to improve physical functioning, but people with rare diseases may find it hard to access or sustain this type of activity. Physical activity includes any body movement and has the scope to bring similar improvements with activities that are accessible and engaging to people living with significant disability. A focus on supporting people to become more active may facilitate lifelong engagement rather than the short term training programmes that have been investigated to date. As common physical, cognitive and psychological challenges are often faced by people with RNCs, these may be helped by increasing engagement in physical activity, irrespective of type of exercise or activity and rare condition. Being more physically active has wide health-related and emotional benefits, beyond improvements at the body structure and functional activity levels. Future interventions should consider activities meaningful to individuals, and how these could be integrated into people's daily life. 


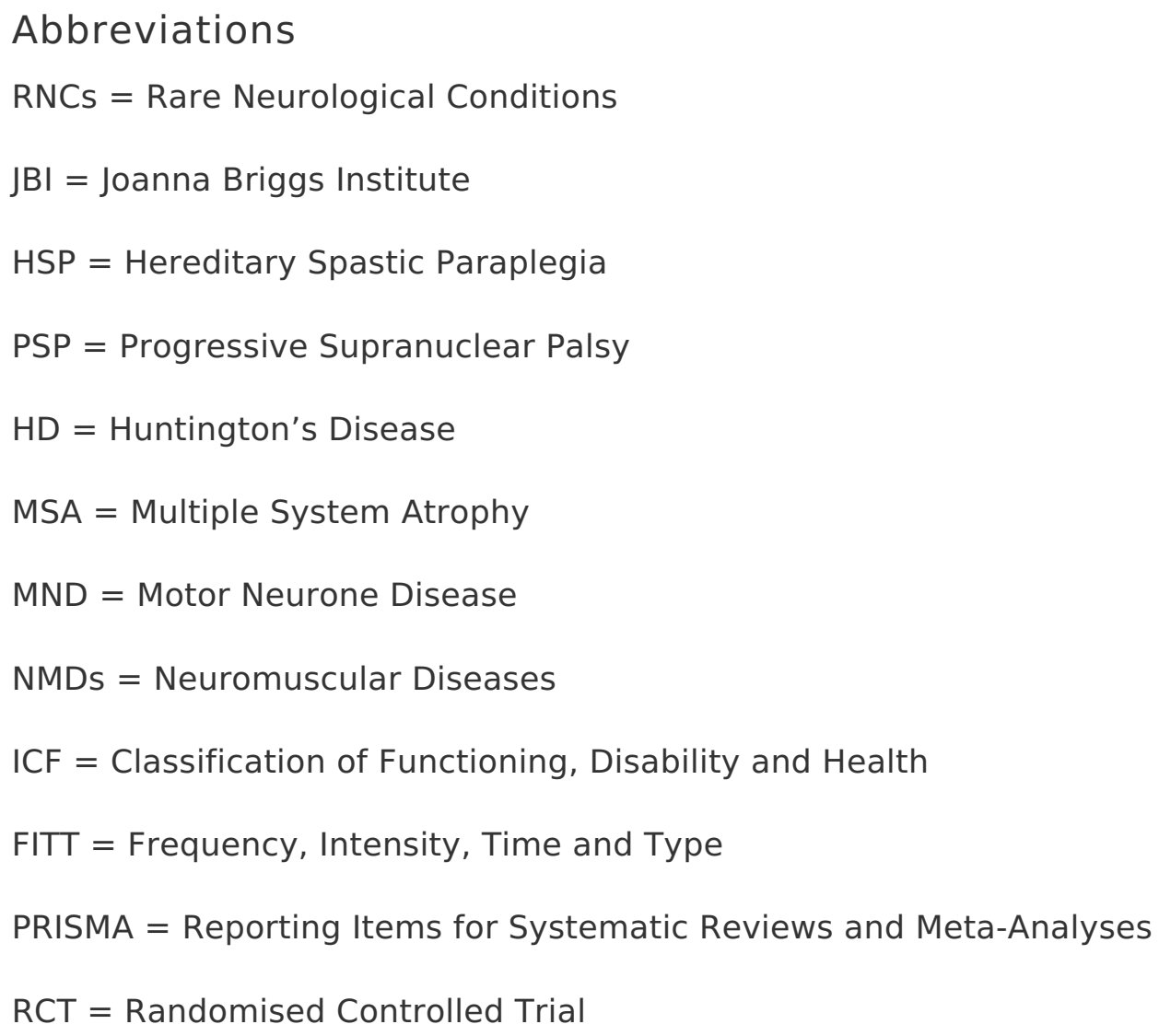


GR was also supported by the National Institute for Health Research University College London Hospitals Biomedical Research Centre.

Authors' contributions: VB conducted the database searches, paper screening and data extraction. GR conducted the paper screening. VB, GR and MB were the major contributors to the writing of this manuscript. All authors contributed to the writing of the manuscript protocol, and read and approved the final manuscript.

Acknowledgements: We would like to acknowledge Kate Brunskill, UCL librarian who assisted with the databases searches.

\section{References}

1. Richter T, Nestler-Parr S, Babela R, Khan ZM, Tesoro T, Molsen E, et al. Rare Disease Terminology and Definitions-A Systematic Global Review: Report of the ISPOR Rare Disease Special Interest Group. Value Health. 2015;18(6):906-914.

2. Rare neurological diseases: a united approach is needed. Lancet Neurol. $2011 ; 10(2): 109$.

3. Simpson A. The Hidden Costs of Rare Diseases: A Feasibility Study. London: Genetic Alliance UK. 2016. https://www.geneticalliance.org.uk/media/2502/hidden-costs-fullreport_21916-v2-1.pdf. Accessed 1 August 2019.

4. Smith B, Kirby N, Skinner B, Wightman L, Lucas R, Foster C. Physical activity for general health benefits in disabled adults: summary of a rapid evidence review for the UK Chief Medical Officers' update of the physical activity guidelines. London: Public Health England; 2018.

5. World Health Organization, Physical Inactivity: A Global Public Health Problem. www.who.int/dietphysicalactivity/factsheet_inactivity/en/. Accessed 15 August 2019.

6. Feasson L, Camdessanché J-P, El Mhandi L, Calmels P, Millet G, editors. Fatigue and 
neuromuscular diseases. Ann Readapt Med Phys. 2006;49(6):375-384.

7. Patterson A, Almeida L, Monari EH, Farmer J, Subramony S. Sleep and Fatigue in Friedreich's Ataxia. Neurology. 2018;90(15).

8. Vuong K, Canning CG, Menant JC, Loy CT. Gait, balance, and falls in Huntington disease. Handb Clin Neurol. 2018;159:251-260.

9. Dharmadasa T, Matamala JM, Huynh W, Zoing MC, Kiernan MC. Motor neurone disease. Handb Clin Neurol. 2018;159:345-57.

10. Lee YEC, Williams DR, Anderson JF. Frontal deficits differentiate progressive supranuclear palsy from P arkinson's disease. J Neuropsychol. 2016;10(1):1-14.

11. Benrud-Larson LM, Sandroni P, Schrag A, Low PA. Depressive symptoms and life satisfaction in patients with multiple system atrophy. Mov Disord. 2005;20(8):951957.

12. Quest: Exercising with a Muscle disease, 2009. https://www.mda.org/sites/default/files/MDA_Quest_Excercise_Package_2009.pdf. Accessed 10 October 2019.

13. Physiotherapy Clinical Guidelines: European Huntington's Disease Network Physiotherapy Working Group, 2013. https://www.hda.org.uk/media/1369/hdphysiotherapy-clinical-guidelines.pdf. Accessed 5 September 2019.

14. Management of the ataxias towards best clinical practice (Third ed.). https://strathprintsstrathacuk/57237/1/Ataxia_UK_2016_Management_of_the_ataxias_ towards_best_clinicalpdf. Accessed 15 August 2019. 2016.

15. World Health Organization, Physical Activity. www.who.int/dietphysicalactivity/pa/en/. Accessed 15 August 2019.

16. Fritz NE, Rao AK, Kegelmeyer D, Kloos A, Busse M, Hartel L, et al. Physical Therapy and Exercise Interventions in Huntington's Disease: A Mixed Methods Systematic 
Review. J Huntingtons Dis. 2017;6(3):217-235.

17. Kloos AD, Fritz NE, Kostyk SK, Young GS, Kegelmeyer DA. Video game play (Dance Dance Revolution) as a potential exercise therapy in Huntington's disease: a controlled clinical trial. Clin Rehabil. 2013;27(11):972-982.

18. Piira A, van Walsem MR, Mikalsen G, Nilsen KH, Knutsen S, Frich JC. Effects of a One Year Intensive Multidisciplinary Rehabilitation Program for Patients with Huntington's Disease: a Prospective Intervention Study. PLoS Curr. 2013;5.

19. Ellis T, Motl RW. Physical activity behavior change in persons with neurologic disorders: overview and examples from Parkinson disease and multiple sclerosis. J Neurol Phys Ther. 2013;37(2):85-90.

20. Glanz K, Bishop DB. The role of behavioral science theory in development and implementation of public health interventions. Annu Rev Public Health. 2010;31:399418.

21. McAuley E, Blissmer B. Self-efficacy determinants and consequences of physical activity. Exerc Sport Sci Rev. 2000;28(2):85-88.

22. Bartels B, Montes J, van der Pol WL, de Groot JF. Physical exercise training for type 3 spinal muscular atrophy. Cochrane Database Syst Rev. 2019;3.

23. Bellofatto M, De Michele G, Iovino A, Filla A, Santorelli FM. Management of Hereditary Spastic Paraplegia: A Systematic Review of the Literature. Front Neurol. 2019;10:3.

24. Smith M, Barker R, Williams G, Carr J, Gunnarsson R. The effect of exercise on highlevel mobility in individuals with neurodegenerative disease: a systematic literature review. Physiother. 2019. In press.

25. Narayanaswami P, Weiss M, Selcen D, David W, Raynor E, Carter G, et al. Evidencebased guideline summary: diagnosis and treatment of limb-girdle and distal dystrophies: report of the guideline development subcommittee of the American 
Academy of Neurology and the practice issues review panel of the American Association of Neuromuscular \& Electrodiagnostic Medicine. Neurology. 2014;83(16):1453-63.

26. Quinn L, Busse M. Development of physiotherapy guidance and treatment-based classifications for people with Huntington's disease. Neurodegener Dis Manag. $2012 ; 2(1): 12-19$.

27. Voet NB, van der Kooi EL, Riphagen, II, Lindeman E, van Engelen BG, Geurts AC. Strength training and aerobic exercise training for muscle disease. Cochrane Database Syst Rev. 2013(7):Cd003907.

28. Gianola S, Pecoraro V, Lambiase S, Gatti R, Banfi G, Moja L. Efficacy of muscle exercise in patients with muscular dystrophy: a systematic review showing a missed opportunity to improve outcomes. Plos one. 2013;8(6):e65414.

29. Ferreira GD, Costa AC, Plentz RD, Coronel CC, Sbruzzi G. Respiratory training improved ventilatory function and respiratory muscle strength in patients with multiple sclerosis and lateral amyotrophic sclerosis: systematic review and metaanalysis. Physiotherapy. 2016;102(3):221-228.

30. The Joanna Briggs institute reviewers' manual 2015: Methodology for JBI scoping reviews. Australia: The Joanna Briggs Institute. 2015.

31. Arksey H, O'Malley L. Scoping studies: towards a methodological framework. Int J Soc Res Methodol. 2005;8(1):19-32.

32. Levac D, Colquhoun H, O'Brien KKJIs. Scoping studies: advancing the methodology. Implement Sci. 2010;5:69.

33. Peters MD, Godfrey CM, Khalil H, Mclnerney P, Parker D, Soares CBJljoe-bh. Guidance for conducting systematic scoping reviews. Int J Evid Based Healthc. 2015;13(3):141146. 
34. World Health Organization, International Classification of Functioning, Disability and Health (ICF). www.who.int/classifications/icf/en/. Accessed 15 August 2019.

35. Stewart LA, Clarke M, Rovers M, Riley RD, Simmonds M, Stewart G, et al. Preferred Reporting Items for Systematic Review and Meta-Analyses of individual participant data: the PRISMA-IPD Statement. Jama. 2015;313(16):1657-65.

36. Lui AJ, Byl NN. A systematic review of the effect of moderate intensity exercise on function and disease progression in amyotrophic lateral sclerosis. JNPT. $2009 ; 33(2): 68-87$

37. Arbesman M, Sheard K. Systematic review of the effectiveness of occupational therapy-related interventions for people with amyotrophic lateral sclerosis. Am J Occup Ther. 2014;68(1):20-26.

38. Dal Bello-Haas V, Florence J, Kloos A, Scheirbecker J, Lopate G, Hayes S, et al. A randomized controlled trial of resistance exercise in individuals with ALS. Neurology. $2007 ; 68(23): 2003-07$.

39. Drory VE, Goltsman E, Reznik JG, Mosek A, Korczyn ADJjotns. J Neurol Sci. 2001;191(1-2):133-137.

40. Dal Bello-Haas V, Florence JM. Therapeutic exercise for people with amyotrophic lateral sclerosis or motor neuron disease. Cochrane Database Syst Rev. 2013(5):Cd005229.

41. Marquer A, Barbieri G, Perennou D. The assessment and treatment of postural disorders in cerebellar ataxia: a systematic review. Ann Rehabil Med. 2014;57(2):6778.

42. Fonteyn EM, Keus SH, Verstappen CC, Schols L, de Groot IJ, van de Warrenburg BP. The effectiveness of allied health care in patients with ataxia: a systematic review. J Neurol. 2014;261(2):251-258. 
43. Cup EHC, Sturkenboom IHWM, Pieterse AJ, Hendricks HT, Van Engelen BGM, Oostendorp RAB, et al. The evidence for occupational therapy for adults with neuromuscular diseases: A systematic review. OTJR. 2008;28(1):12-18.

44. Ng L, Khan F. Multidisciplinary care for adults with amyotrophic lateral sclerosis or motor neuron disease. Cochrane Database Syst Rev. 2009;12.

45. Ydemann M, Eddelien HS, Lauritsen AO. Treatment of critical illness polyneuropathy and/or myopathy - a systematic review. Dan Med J. 2012;59(10):A4511.

46. Habers GE, Takken T. Safety and efficacy of exercise training in patients with an idiopathic inflammatory myopathy--a systematic review. Rheumatology (Oxford). $2011 ; 50(11): 2113-24$

47. Corrado B, Ciardi G, Bargigli C. Rehabilitation Management of the Charcot-MarieTooth Syndrome: A Systematic Review of the Literature. Medicine. 2016;95(17):e3278.

48. Sman AD, Hackett D, Fiatarone Singh M, Fornusek C, Menezes MP, Burns J. Systematic review of exercise for Charcot-Marie-Tooth disease. J Peripher Nerv Syst. $2015 ; 20(4): 347-362$.

49. Arsenault NS, Vincent P-O, Yu Bai He S, Bastien R, Sweeney A, Sylvia Z. Influence of Exercise on Patients with Guillain-Barré Syndrome: A Systematic Review. Physiother Can. 2016;68(4):367-376.

50. Koopman FS, Uegaki K, Gilhus NE, Beelen A, de Visser M, Nollet F. Treatment for postpolio syndrome. Cochrane Database Syst Rev. 2011(2):Cd007818.

51. Khan F, Amatya B. Rehabilitation interventions in patients with acute demyelinating inflammatory polyneuropathy: a systematic review. Eur J Phys Rehabil Med. 2012;48(3):507-522.

52. Quinn L, Busse M. Development of physiotherapy guidance and treatment-based 
classifications for people with Huntington's disease. Neurodegener Dis Manag.

$2012 ; 2(1): 12-19$.

53. Milne SC, Corben LA, Georgiou-Karistianis N, Delatycki MB, Yiu EM. Rehabilitation for Individuals With Genetic Degenerative Ataxia: A Systematic Review. Neurorehabil Neural Repair. 2017;31(7):609-622.

54. Trujillo-Martin MM, Serrano-Aguilar P, Monton-Alvarez F, Carrillo-Fumero R.

Effectiveness and safety of treatments for degenerative ataxias: a systematic review. Mov Disord. 2009;24(8):1111-24.

55. Hajjar SH, Cooper JK. Progressive supranuclear palsy treatment-A systematic review. Basal Ganglia. 2016;6(2):75-78.

56. Intiso D, Bartolo M, Santamato A, Di Rienzo F. The Role of Rehabilitation in Patients With Progressive Supranuclear Palsy: A Narrative Review. PM R. 2018;10(6):636-645.

57. Young $\mathrm{P}$, De Jonghe $\mathrm{P}$, Stogbauer F, Butterfass-Bahloul T. Treatment for CharcotMarie-Tooth disease. Cochrane Database Syst Rev. 2008(1):Cd006052.

58. Quinlivan R, Vissing J, Hilton-Jones D, Buckley J. Physical training for McArdle disease. Cochrane Database Syst Rev. 2011(12):Cd007931.

59. Eidenberger M, Nowotny S. Inspiratory muscle training in patients with Amyotrophic Lateral Sclerosis: A systematic review. NeuroRehabilitation. 2014;35(3):349-61.

60. Muscular Dystrophy UK. https://www.musculardystrophyuk.org/about-muscle-wastingconditions/. Accessed 15 August 2019.

61. Sato M, Kannari K, Tomari M, Kawaguchi T. Physical therapy intervention with a low frequency of exercise for a patient with a complicated form of hereditary spastic paraplegia: a case report. J Phys Ther Sci. 2019;31(7):545-549.

62. Zhang Y, Roxburgh R, Huang L, Parsons J, Davies TC. X. Gait Posture. 2014;39(4):1074-1079. 
63. Bertolucci F, Di Martino S, Orsucci D, lenco EC, Siciliano G, Rossi B, et al. Robotic gait training improves motor skills and quality of life in hereditary spastic paraplegia. NeuroRehabilitation. 2015;36(1):93-99.

64. Seo HG, Oh B-M, Kim K. Robot-assisted gait training in a patient with hereditary spastic paraplegia. PM\&R. 2015;7(2):210-213.

65. Orphanet Rare Diseases Portal. www.orpha.net/consor/cgi-bin/index.php?Ing=EN. Accessed 15 August 2019.

66. Riebe D, Ehrman JK, Liguori G, Magal M. American College of Sports Medicine, ACSM's guidelines for exercise testing and prescription. Wolters Kluwer (Tenth ed.); 2018.

67. Michie S, van Stralen MM, West R. The behaviour change wheel: a new method for characterising and designing behaviour change interventions. Implement Sci. 2011;6(42):1-11.

68. Sangelaji B, Smith CM, Paul L, Sampath KK, Treharne GJ, Hale LA. The effectiveness of behaviour change interventions to increase physical activity participation in people with multiple sclerosis: a systematic review and meta-analysis. Clin Rehabil. $2016 ; 30(6): 559-576$.

69. Hankonen N, Sutton S, Prevost AT, Simmons RK, Griffin SJ, Kinmonth AL, et al. Which behavior change techniques are associated with changes in physical activity, diet and body mass index in people with recently diagnosed diabetes? Ann Behav Med. $2015 ; 49(1): 7-17$.

70. Ryan JM, Fortune J, Stennett A, Kilbride C, Lavelle G, Hendrie W, et al. Safety, feasibility, acceptability and effects of a behaviour-change intervention to change physical activity behaviour among people with multiple sclerosis: Results from the iStep-MS randomised controlled trial. Mult Scler J. 2019:1352458519886231.

71. Sit JW, Chair SY, Chan Yip CW, Choi KC, Lee DT, Leung KP, et al. Effect of health 
empowerment intervention for stroke self-management on behaviour and health in stroke rehabilitation patients. Hong Kong Med J. 2018;24 Suppl 2(1):12-15.

72. Hallward L, Patel N, Duncan LR. Behaviour change techniques in physical activity interventions for men with prostate cancer: A systematic review. J Health Psychol. 2018:1359105318756501.

73. Montes J, Garber CE, Kramer SS, Montgomery MJ, Dunaway S, Kamil-Rosenberg S, et al. A Randomized, Controlled Clinical Trial of Exercise in Patients with Spinal Muscular Atrophy: Methods and Baseline Characteristics. J Neuromuscul Dis. 2014;1(2):151-161.

74. Dauwan M, Begemann MJ, Slot MI, Lee EH, Scheltens P, Sommer IE. Physical exercise improves quality of life, depressive symptoms, and cognition across chronic brain disorders: a transdiagnostic systematic review and meta-analysis of randomized controlled trials. J Neurol. 2019:1-25.

75. Miyai I, Ito M, Hattori N, Mihara M, Hatakenaka M, Yagura H, et al. Cerebellar ataxia rehabilitation trial in degenerative cerebellar diseases. Neurorehabil Neural Repair. $2012 ; 26(5): 515-522$.

76. Wiering B, de Boer D, Delnoij D. Patient involvement in the development of patientreported outcome measures: a scoping review. Health Expect. 2017;20(1):11-23.

\section{Tables}

Table 1. Review characteristics of included studies 


\begin{tabular}{|c|c|c|}
\hline $\begin{array}{l}\text { Review } \\
\text { characteristics }\end{array}$ & & Count \\
\hline \multirow[t]{5}{*}{ Review type } & Narrative synthesis & 16 \\
\hline & Cochrane reviews & 6 \\
\hline & Meta-analysis & 2 \\
\hline & Systematic review as part of practice recommendations & 2 \\
\hline & Mixed-methods & 1 \\
\hline \multirow[t]{6}{*}{ Year publication } & 2008 & 2 \\
\hline & $2009-2010$ & 3 \\
\hline & 2011-2012 & 5 \\
\hline & $2013-2014$ & 8 \\
\hline & $2015-2016$ & 6 \\
\hline & $2017-2018$ & 3 \\
\hline \multirow[t]{5}{*}{ Disease studied } & Neuromuscular diseases & 13 \\
\hline & Motor neurone disease & 6 \\
\hline & Ataxias & 4 \\
\hline & Huntington's disease & 2 \\
\hline & Progressive supranuclear palsy & 2 \\
\hline \multirow[t]{7}{*}{ Review aim } & Evidence for treatment (any type) & 9 \\
\hline & Safety and/or efficacy for exercise training & 6 \\
\hline & Efficacy for rehabilitation & 4 \\
\hline & Safety and/or efficacy for strength and/or aerobic training & 3 \\
\hline & Efficacy for respiratory muscle training & 2 \\
\hline & Evidence for occupational therapy & 2 \\
\hline & Efficacy for multidisciplinary interventions & 1 \\
\hline \multirow{4}{*}{$\begin{array}{l}\text { Number of studies } \\
\text { for each } \\
\text { systematic } \\
\text { review }\end{array}$} & $1-5$ & 18 \\
\hline & $6-10$ & 3 \\
\hline & $11-15$ & 4 \\
\hline & $16-20$ & 2 \\
\hline
\end{tabular}

Table 2. Number of reviews per condition and FITT characteristics for combined interventions 


\begin{tabular}{|c|c|c|c|}
\hline Reviews per condition & Frequency & Intensity (per session) & $\bar{T}$ \\
\hline Neuromuscular diseases $\mathrm{N}=10$ & 2 to 5 times a week & 10 to 180 minutes & $\overline{1}$ \\
\hline Moto neurone disease $\mathrm{N}=4$ & $\begin{array}{l}2 \text { to } 5 \text { times a week (when } \\
\text { reported) }\end{array}$ & 15 minutes (mostly not reported) & 6 \\
\hline Ataxias $\mathrm{N}=4$ & $\begin{array}{l}1 \text { to } 7 \text { times a week (when } \\
\text { reported) }\end{array}$ & $\begin{array}{l}15 \text { to } 120 \text { minutes (mostly not } \\
\text { reported) }\end{array}$ & 4 \\
\hline Huntington's disease $\mathrm{N}=2$ & 1 to 6 times a week & 30 minutes to 8 hours (intensive) & 1 \\
\hline $\begin{array}{l}\text { Progressive supranuclear palsy } N= \\
2\end{array}$ & 2 to 7 times a week & 45 to 60 minutes & 4 \\
\hline
\end{tabular}

Table 3. ICF domains identified for each study

\begin{tabular}{|c|c|c|c|c|c|c|}
\hline Authors & $\begin{array}{l}\text { Condition } \\
\text { included }\end{array}$ & $\begin{array}{l}\text { Body- } \\
\text { structure }\end{array}$ & $\begin{array}{l}\text { Body- } \\
\text { function }\end{array}$ & $\begin{array}{l}\text { Activit } \\
\mathrm{y}\end{array}$ & $\begin{array}{l}\text { Participatio } \\
\text { n }\end{array}$ & $\overline{\text { Disease-s| }}$ \\
\hline $\begin{array}{l}\text { Voet et al. } \\
\text { (2013) }\end{array}$ & $\begin{array}{l}\text { Muscle diseases } \\
\text { (myotonic } \\
\text { dystrophy, } \\
\text { polymyositis and } \\
\text { dermatomyositis, } \\
\text { facioscapulohumer } \\
\text { al muscular } \\
\text { dystrophy, } \\
\text { mitochondrial } \\
\text { myopathy) }\end{array}$ & & $\checkmark$ & & $\checkmark$ & \\
\hline Cup et al. (2008) & $\begin{array}{l}\text { Myotonic dystrophy } \\
\text { and Welander } \\
\text { distal myopathy }\end{array}$ & & $\bar{J}$ & $\sqrt{\prime}$ & $\bar{J}$ & \\
\hline $\begin{array}{l}\text { Gianola et al. } \\
(2013)\end{array}$ & Muscular dystrophy & & $\bar{J}$ & $\bar{s}$ & & \\
\hline $\begin{array}{l}\text { Narayanaswami } \\
\text { et al. (2014) }\end{array}$ & $\begin{array}{l}\text { Welander distal } \\
\text { myopathy, Becker } \\
\text { muscular } \\
\text { dystrophy, Limb- } \\
\text { girdle muscular } \\
\text { dystrophies, } \\
\text { Hereditary } \\
\text { inclusion body } \\
\text { myopathies }\end{array}$ & $\sqrt{ }$ & $\bar{J}$ & & & \\
\hline $\begin{array}{l}\text { Habers and } \\
\text { Takken (2011) }\end{array}$ & $\begin{array}{l}\text { Idiopathic } \\
\text { inflammatory } \\
\text { myopathy } \\
\text { (dermatomyositis, } \\
\text { polymyositis, and } \\
\text { inclusion body } \\
\text { myositis) }\end{array}$ & $\bar{J}$ & $\bar{J}$ & & 2 & \\
\hline $\begin{array}{l}\text { Ydemann, } \\
\text { Eddelien and } \\
\text { Lauritsen (2012) }\end{array}$ & $\begin{array}{l}\text { Critical illness } \\
\text { myopathy and } \\
\text { polyneuropathy }\end{array}$ & & $\bar{s}$ & $\bar{J}$ & $\bar{s}$ & \\
\hline
\end{tabular}




\begin{tabular}{|c|c|c|c|c|c|c|}
\hline $\begin{array}{l}\text { Young et al. } \\
(2008)\end{array}$ & $\begin{array}{l}\text { Charcot-Marie- } \\
\text { Tooth disease }\end{array}$ & & $\checkmark$ & $\checkmark$ & & \\
\hline $\begin{array}{l}\text { Sman et al. } \\
(2015)\end{array}$ & $\begin{array}{l}\text { Charcot-Marie- } \\
\text { Tooth disease }\end{array}$ & $\bar{s}$ & $\bar{J}$ & $\bar{l}$ & & $\bar{J}$ \\
\hline $\begin{array}{l}\text { Corrado, Ciardi } \\
\text { and Bargigli } \\
\text { (2016) }\end{array}$ & $\begin{array}{l}\text { Charcot-Marie- } \\
\text { Tooth disease }\end{array}$ & $\bar{J}$ & $\bar{J}$ & $\bar{l}$ & & \\
\hline $\begin{array}{l}\text { Quinlivan et al. } \\
(2011)\end{array}$ & McArdle disease & $\bar{l}$ & $\bar{J}$ & & & \\
\hline $\begin{array}{l}\text { Koopman et al. } \\
(2015)\end{array}$ & Postpolio syndrome & & $\bar{J}$ & $\bar{l}$ & & \\
\hline $\begin{array}{l}\text { Arsenault et al. } \\
\text { (2016) }\end{array}$ & $\begin{array}{l}\text { Guillain-Barre' } \\
\text { Syndrome }\end{array}$ & & $\sqrt{ }$ & $\sqrt{ }$ & $\bar{s}$ & $\bar{J}$ \\
\hline $\begin{array}{l}\text { Khan and } \\
\text { Amatya (2012) }\end{array}$ & $\begin{array}{l}\text { Guillain-Barre' } \\
\text { Syndrome }\end{array}$ & & $\sqrt{ }$ & $\bar{v}$ & $\bar{l}$ & \\
\hline $\begin{array}{l}\text { Dal Bello-Haas et } \\
\text { al. (2013) }\end{array}$ & $\begin{array}{l}\text { Motor-neuron } \\
\text { disease }\end{array}$ & & $\bar{J}$ & & $\bar{l}$ & 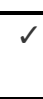 \\
\hline $\begin{array}{l}\text { Lui and Nancy } \\
\text { (2009) }\end{array}$ & $\begin{array}{l}\text { Motor-neuron } \\
\text { disease }\end{array}$ & & $\checkmark$ & & & $\checkmark$ \\
\hline $\begin{array}{l}\text { Eidenberger and } \\
\text { Nowotny (2014) }\end{array}$ & $\begin{array}{l}\text { Motor-neuron } \\
\text { disease }\end{array}$ & & $\bar{J}$ & $\checkmark$ & $\sqrt{\prime}$ & $\bar{J}$ \\
\hline $\begin{array}{l}\text { Ferreira et al. } \\
(2016)\end{array}$ & $\begin{array}{l}\text { Motor-neuron } \\
\text { disease }\end{array}$ & & $\bar{J}$ & $\bar{v}$ & & \\
\hline $\begin{array}{l}\text { Abersman and } \\
\text { Sheard (2014) }\end{array}$ & $\begin{array}{l}\text { Motor-neuron } \\
\text { disease }\end{array}$ & & $\bar{J}$ & & $\bar{s}$ & $\bar{v}$ \\
\hline $\begin{array}{l}\mathrm{Ng} \text { and Khan } \\
(2009)\end{array}$ & $\begin{array}{l}\text { Motor-neuron } \\
\text { disease }\end{array}$ & & & & $\bar{s}$ & $\bar{v}$ \\
\hline $\begin{array}{l}\text { Quinn and Busse } \\
\text { (2012) }\end{array}$ & $\begin{array}{l}\text { Huntington's } \\
\text { disease }\end{array}$ & & $\bar{J}$ & $\bar{v}$ & $\bar{s}$ & $\bar{v}$ \\
\hline Fritz et al. (2017) & $\begin{array}{l}\text { Huntington's } \\
\text { disease }\end{array}$ & & $\bar{J}$ & $\bar{v}$ & & \\
\hline $\begin{array}{l}\text { Trujillo-Martı'n et } \\
\text { al. (2009) }\end{array}$ & $\begin{array}{l}\text { Spinocerebellar } \\
\text { ataxia }\end{array}$ & & $\bar{J}$ & & & \\
\hline $\begin{array}{l}\text { Fonteyn et al. } \\
\text { (2014) }\end{array}$ & Cerebellar Ataxia & & $\bar{J}$ & $\bar{l}$ & $\bar{l}$ & $\sqrt{ }$ \\
\hline $\begin{array}{l}\text { Milne et al. } \\
(2017)\end{array}$ & $\begin{array}{l}\text { Genetic } \\
\text { degenerative } \\
\text { ataxia }\end{array}$ & & $\sqrt{ }$ & $\bar{l}$ & $\bar{l}$ & $\checkmark$ \\
\hline $\begin{array}{l}\text { Marquer, Barbieri } \\
\text { and Pe'rennou } \\
\text { (2014) }\end{array}$ & Cerebellar Ataxia & & $\bar{J}$ & & & \\
\hline $\begin{array}{l}\text { Hajjar and } \\
\text { Cooper (2016) }\end{array}$ & $\begin{array}{l}\text { Progressive } \\
\text { supranuclear palsy }\end{array}$ & & $\bar{J}$ & $\bar{s}$ & & \\
\hline $\begin{array}{l}\text { Intiso et al. } \\
\text { (2018) }\end{array}$ & $\begin{array}{l}\text { Progressive } \\
\text { supranuclear palsy }\end{array}$ & & $\sqrt{\prime}$ & $\bar{l}$ & & $\sqrt{\top}$ \\
\hline
\end{tabular}

\section{Figures}




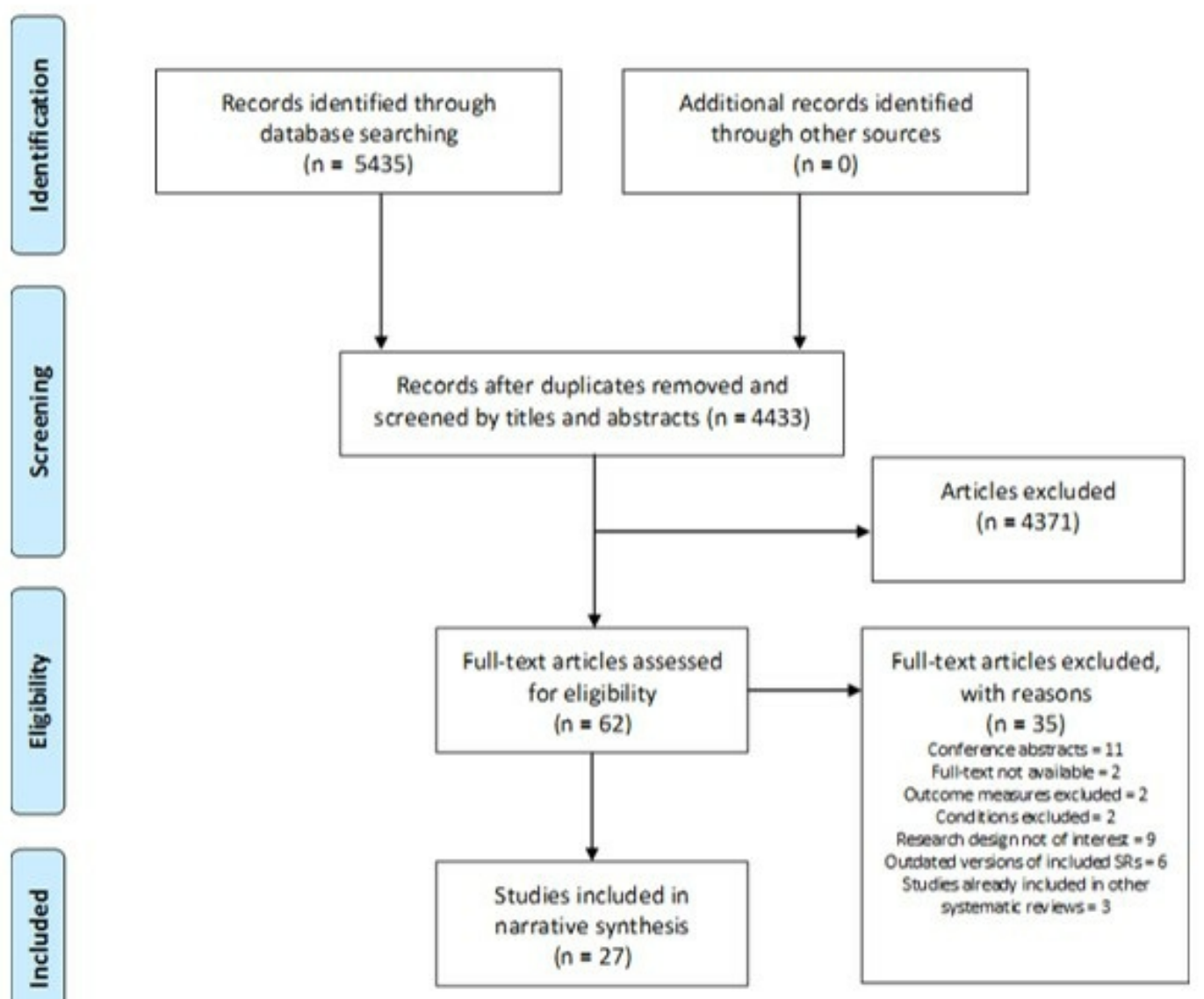

Figure 1

PRISMA flow diagram 


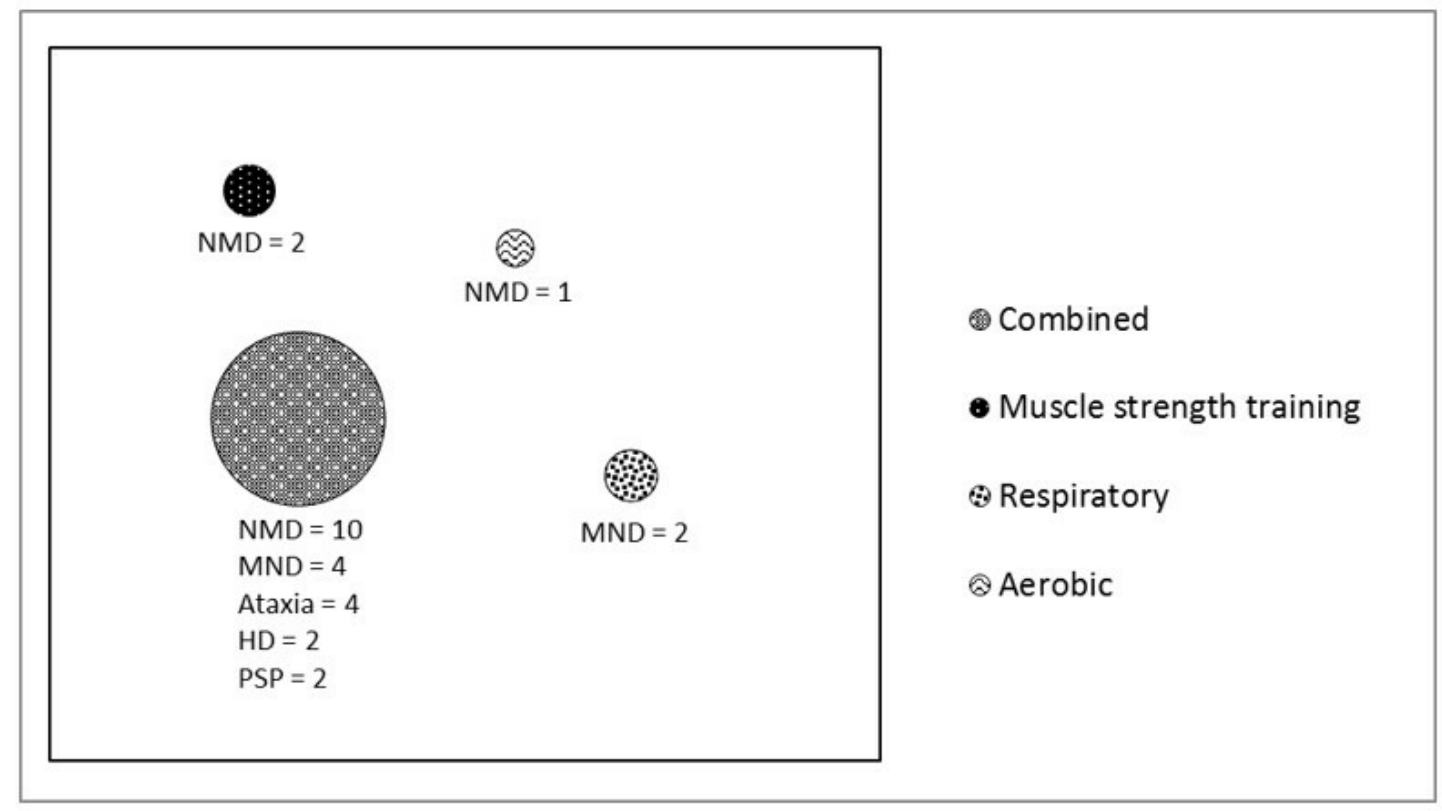

Figure 2

Summary of types of interventions per condition

\section{Supplementary Files}

This is a list of supplementary files associated with this preprint. Click to download.

Buscemi et al_Additional file 2.docx

Buscemi et al_Additional file 3.docx

Buscemi et al_Additional file 1.docx

Buscemi et al_Additional file 5.docx

Buscemi et al_Additional file 4.docx 